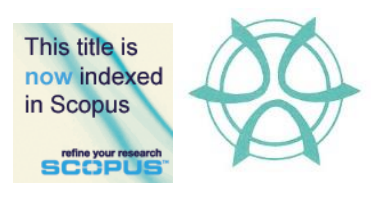

PLANNING MALAYSIA:

Journal of the Malaysian Institute of Planners

VOLUME 15 ISSUE 3 (2017), Page 179 - 192

\title{
PREFERENCE FOR PURPOSE BUILT RETIREMENT NEIGHBOURHOOD AMONG THE CHINESE ELDERLY IN SMALL TOWNS IN MALAYSIA
}

\author{
Norhaslina Hassan $^{1}, \&$ Tan Jiaqi ${ }^{2}$ \\ ${ }^{1,2}$ Department of Geography, Faculty of Arts and Social Sciences \\ UNIVERSITY OF MALAYA.
}

\begin{abstract}
The popularity of retirement villages in many developed countries provides a potential market in Malaysia, which is rapidly facing an ageing society. However, little is known about the purpose-built retirement neighbourhood especially its desirability among the local elderly and niche in smaller towns which are poised to reap economic benefits from their locational advantage trending the retirement industry in the region. This study aims to firstly, explore the desirability of retirement neighbourhood among the Chinese elderly in Segamat using semistructured interviews and secondly, identify the niche market of such neighbourhood and its potential contribution to support development strategy of the town. The preference for retirement neighbourhood as an alternative living arrangement among the Chinese elderly in Segamat indicates its good potential as a new source of economic growth but requires that public planning facilitates efficient land development process and increase amenity and services for all especially the elderly.
\end{abstract}

Keyword: Chinese elderly, local economic development, Malaysia, retirement neighbourhood, small towns

Date Received: $9^{\text {th }}$ May 2017

Date of Acceptance: $28^{\text {th }}$ September 2017 
Norhaslina Hassan, \& Tan Jiaqi

Preference for Purpose Built Retirement Neighbourhood Among the Chinese Elderly in Small Towns in Malaysia

\section{INTRODUCTION}

According to the Department of Statistics Malaysia, the elderly population in the country in 2000 has reached 1.4 million, which accounted to $5.0 \%$ of the total population. The trend is expected to increase to $10.4 \%$ in 2035. It is projected that Malaysia will become an aging society in less than 25 years. Data regarding fertility rate and household size in Malaysia further reveals that the number of small families and old age dependency ratio in Malaysia are expected to increase rapidly (Department of Statistics Malaysia, 2010). In view of the current demographic trend of increasingly smaller family units and higher participation in the labour force among women as urbanization progresses, the younger generation with double income family will result in a high possibility of their elderly parents being sent to the nursing home (Lim, Noralfishah \& Baldry, 2013). While many nursing homes and care centres have been provided by both the public and private sectors, these are dreaded as retirement places for most elderly. They cite poor quality of care, erosion of personal autonomy, loss of meaning and sense of belonging staying in nursing homes (Wong, 2011; Chan 2011; Lim, Noralfishah \& Baldry, 2013). Prosperity, however, are transforming traditional family practices and ways of meeting obligations are being "renegotiated and constructed" within the prevailing socioeconomic structures and policies (Phillipson, 2010). Retirement institutions now emerge as privileged destinations where paying the high cost of professional care is viewed as a powerful expression of filial piety among the eastern societies (Izuhara, 2010).

As the phenomenon that the elderly need to be independent becomes pervasive in Malaysia, alternative retirement lifestyles such as retirement neighbourhoods provide a realistic option in order to provide them much convenience in many aspects. Retirement village benefits include community living, security, independence and communality, and increased quality of life (Stimson \& McCrea, 2004; Crisp et al., 2013). Planned retirement communities designed to attract in-migration of retirees have long been advocated as an economic development strategy for non-metropolitan areas which are facing challenges of population ageing and slow economic development (Glasgow, 1990; Fagan \& Longino, 1993; Stallman \& Jones, 1995). Retirement communities may also atrract older migrants that tend to have steady incomes that are not vulnerable to economic cycles (Stallmann \& Siegel, 1995). It is for similar reason that the real estate industry was particularly keen on the rapidly growing retirement industry in Southeast Asia especially during the economic crisis and pursued as national development strategy by the states (Toyota $\&$ Xiang, 2012). Seen from this perspective, the "Silver Tsunami" of Asia and particularly of Singapore presents an economic possibility for the neighbouring Johor Bahru metropolitan area (Ormond, 2014) as well as the small towns in its vicinity such as Segamat. The issue is to what extent are the non-metropolitan local authorities able to facilitate private sector investment in the purposely built 
PLANNING MALAYSIA

retirement neighbourhood in their resource rich areas; firstly to stimulate local economic development and, secondly, to expand the choice of retirement lifestyles for quality in place ageing?

This study aims to explore the desirability of retirement neighbourhood as an alternative retirement lifestyle among the Chinese elderly in Segamat. This study further explore the niche market in the elderly housing sector in the area focusing on the government's role in increasing amenity and services through public sector planning, while at the same time facilitating private sector initiatives for the development of the purposely built retirement neighbourhood.

\section{DEMOGRAPHIC TREND ON AGEING IN MALAYSIA}

According to the Department of Statistics Malaysia (2010), the annual growth rate of the population would decline from $1.8 \%$ in 2010 to $0.6 \%$, but the elderly people aged 60 and above will increase drastically, from $5.0 \%$ of the population in 2010 to $6.8 \%$ in 2020 and to $10.4 \%$ in 2035 . One major reason contributing to the ageing population, especially of small towns, is the out migration of the younger generation. Although the net impact of migration on population ageing at the national level is usually minimal (United Nation, 2013), its effect on localities is profound as internal movements are more prevalent at this scale. The migrants, who are younger, tend to leave their hometown to seek better prospects in the larger cities in the states of Selangor, Melaka and Pulau Pinang. The big cities in Malaysia continue to benefit from in-migration of talents and resources at the expense of the smaller hometowns, a threat which Segamat is facing.

Segamat is a small town and a district located in the north of the state of Johor in Malaysia. It is located approximately 172 kilometers from Johor Bahru, and about 179 kilometers from Singapore. The Johor Structure Plan 2020 estimated the population of the district to increase to 218,313 people in 2020 with an average population growth rate of between $0.44 \%$ and $0.95 \%$ per year (Department of Town and Country Planning (DTCP), 2010). In 2010, it was recorded that out of 183,985 Segamat residents, 21,034 were elderly aged 60 and above, which accounted to $11.5 \%$ of the total Segamat population (Department of Statistics Malaysia, 2000; 2010) qualifying it as an ageing society. Apart from outmigration, other factors such as low fertility rate, longevity, decreasing family size and inadequate job opportunities also contributed to the ageing society in Segamat (Tan, 2014).

\section{ELDERLY LIVING ARRANGEMENT}

Living arrangements and familial support are intricately linked, given that the traditional way to deliver care to elders in terms of emotional, financial, physical and intergenerational relationship was facilitated by co-residence (Izuhara, 2010). Unfortunately, co-residence may not be sustainable in the foreseeable future as the current trends of urbanization, modernization and migration for work have 
Norhaslina Hassan, \& Tan Jiaqi

Preference for Purpose Built Retirement Neighbourhood Among the Chinese Elderly in Small Towns in Malaysia

resulted in the young adults to leave their elderly parents at home and living apart. The double-income and smaller families of today find that taking care of their elderly parents becomes increasingly challenging due to the ties of works and other social engagements (Lim, Noralfishah \& Baldry, 2013). As their children are less able to support them, nursing homes care centres and other elderly type of settlements thus, become an option for the elderly living arrangement.

\section{Retirement Neighbourhood as an Alternative Elderly Lifestyle}

The concept of nursing cares has undergone changes, shifting to include a wider concept of retirement communities, villages and neighbourhoods. A retirement neighbourhood in essence, is a housing complex designed for older adults who are generally able to care for themselves. Hunt et al. (1984) identify the three main elements of retirement communities consisting of housing, services and residents, and that they are "aggregations of housing units and at least a minimal level of services planned for older people who are predominantly healthy and retired" (pp. 4-5). Retirement communities and villages nowadays are described as planned, low-density, age-segregated development, constructed by private capital, offering extensive recreational services and relatively low-cost housing for the elderly (Reynolds \& Beamish, 2003).

Besides assistance from homecare agencies, opportunities for activities and socialization are well provided in the retirement neighbourhood. Services such as shops, hospitals and entertainment facilities could be serviced by young people making such retirement neighbourhoods inclusive of the outside world. Retirement neighbourhoods thus are not merely an elderly town, but also environments that encourage social interaction between old and young generations (Bernard et al., 2011).

\section{METHODS}

Preference for retirement neighbourhood among Chinese elderly in the Segamat small town in this study was facilitated by semi-structured face-to-face interviews with a sample of 98 Chinese elderly respondents conducted in 2014. This number goes well beyond the minimum "saturation point" that occurs around 15 participants (Latham, 2013) where additional participants does not provide any additional insights. The respondents were conveniently selected either in their own homes or in public places to aid the exploratory analysis with each interview session lasting roughly one hour. A questionnaire consisting of 3 sections relating to personal background, present living arrangements and medical condition of the respondents; questions relating to life satisfaction of the personal, family and social life of the respondents and lastly, their preference for retirement neighbourhood over nursing home. Responses were based on a scale of 1-5, with 1 being "strongly dissatisfied" and 5 being "strongly satisfied". The Likert summated scale was then constructed and aggregated scores of life satisfaction 
were reclassified into 4 main sub-scales for satisfaction levels as "very satisfied", "fairly satisfied", "dissatisfied" and "very dissatisfied". Descriptive statistical analysis using cross tabulations and Chi-square tests were employed to identify relationships between life satisfaction and demographic characteristics of the elderly respondents, as well as their preference for retirement neighbourhood. Significant value $(\mathrm{p}<0.05)$ in Chi-square test was used as an important value judgment of the relationship between studied variables.

\section{RESULTS AND DISCUSSION}

The elderly respondents who were interviewed consisted of 55\% males and $45 \%$ females; $32 \%$ in the age group of 55 to 59 (early retiree), about more than half in the age group 60 to 79 years old (retiree), while those over 80 years old (older retiree) accounted to only 7\%. More than half of the respondents were locals and had been staying in Segamat for about 60 years. $41 \%$ of the respondents had either nil or primary education, while those who had secondary education accounted to almost half of the sample (49\%); whereas $10 \%$ of the respondents had tertiary education. In their living arrangements, the majority of the elderly respondents (54\%) were found to live with their spouse only. $25 \%$ of the elderly respondents live with their children and $7 \%$ live with their relatives. A surprisingly large proportion of the elderly respondents, i.e. $14 \%$ live alone.

More than half of the elderly respondents interviewed (57\%) were still earning their own income, $38 \%$ receive allowance from either their children or relatives, while the rest $(5 \%)$ receive income from the government welfare scheme or other organizations. $41 \%$ of the respondents were economically inactive. Most of the elderly respondents who were still working or partially working accounted to $23 \%$ and $33 \%$ respectively. In the sample, $63 \%$ of the elderly respondents can still walk unaided, $14 \%$ of them were unable to walk unaided, while $23 \%$ of the elderly respondents walk unaided occasionally. In their self-evaluation of own health conditions, more than half of the elderly respondents considered themselves to be in 'excellent' or 'good health'. Those who assessed their health to be 'fair' and 'poor' accounted to $29 \%$ and $1 \%$ respectively. The majority of the elderly respondents indicated that they were fairly satisfied with their life with the reported mean of 3.14 and 0.51 standard deviation.

$96 \%$ of the elderly respondents interviewed preferred retirement neighbourhood than nursing home as their alternative options of retirement life (Table 1). The overwhelming attraction of the new concept of retirement lifestyle was unmistakably due to the infrastructure, facilities and services to support modern elderly lifestyle, but the widespread negative perception regarding the nursing homes could not be denied. Most of the respondents viewed that nursing homes were unable to fulfil the needs of the elderly and depersonalizing despite 
Norhaslina Hassan, \& Tan Jiaqi

Preference for Purpose Built Retirement Neighbourhood Among the Chinese Elderly in Small Towns in Malaysia

the professional medical health care. According to the elderly respondents, staying in nursing homes was "a shame" as they have children and wealth.

Table 1 Preference for Retirement Neighbourhoods among the Elderly Respondents

\begin{tabular}{|c|c|c|c|c|}
\hline Variables & $\begin{array}{c}\text { Significant } \\
\text { Levels }\end{array}$ & $\begin{array}{l}\text { Total } \\
(\%)\end{array}$ & $\begin{array}{c}\text { Retirement } \\
\text { Neighbourhoods } \\
(\%)\end{array}$ & $\begin{array}{c}\text { Nursing } \\
\text { Homes (\%) }\end{array}$ \\
\hline Total & & 100.0 & 96.0 & 4.0 \\
\hline Age Groups & $* 0.000$ & & & \\
\hline $55-59$ (early retiree) & & 32.0 & 33.3 & 0.0 \\
\hline $60-79($ retiree $)$ & & 61.0 & 62.5 & 25.0 \\
\hline$>80$ (older retiree) & & 7.0 & 4.2 & 75.0 \\
\hline Gender & $* 0.038$ & & & \\
\hline Male & & 55.0 & 57.3 & 0.0 \\
\hline Female & & 45.0 & 42.7 & 100.0 \\
\hline Source of income & $* 0.000$ & & & \\
\hline Relatives or & & 38.0 & 39.6 & 0.0 \\
\hline Children & & 57.0 & 58.3 & 25.0 \\
\hline Own Income & & 5.0 & 2.1 & 75.0 \\
\hline Others & & & & \\
\hline Satisfaction levels & $* 0.002$ & & & \\
\hline Very dissatisfied & & 0.0 & 0.0 & 0.0 \\
\hline Dissatisfied & & 7.0 & 5.2 & 50.0 \\
\hline Fairly satisfied & & 72.0 & 72.9 & 50.0 \\
\hline Very satisfied & & 21.0 & 21.9 & 0.0 \\
\hline
\end{tabular}

*Significant Value of the Chi-Square, $\mathrm{p}=(<0.05)$;

Source: Field Study, 2014

Only four variables showed significant differences in the preference for retirement neighbourhoods among the elderly; these being age group, gender, source of income and levels of satisfaction. In other words, the preference for retirement neighbourhood concept is pervasive among the elderly respondents regardless of education levels, birth place, length of stay in the locality, income, living arrangement, working status, mobility or even medical conditions. Table 1 shows that $62.5 \%$ of the respondents in the age group 60-79 tended to be more receptive to the idea of retirement neighbourhoods than the early retiree (33.3\%), whereas only $4.2 \%$ of the older retiree (> $>0$ years) would even entertain the new idea. Preference for the alternative retirement settlement also tended to be associated with elderly males (57.3\%) compared to females (42.7\%). Respondents who reported to have own income (58.3\%) and received allowance from family or relatives $(39.6 \%)$ tended to also prefer retirement neighbourhoods to nursing homes compared to elderly respondents who depended on other sources of income $(2.1 \%)$. It is interesting to note that preference for retirement neighbourhood among different sources of income received by the elderly is 
PLANNING MALAYSIA

mediated by age; since the younger elderly (50-59 and 60-79) tended to be associated with having own income or transfers from children or relatives whereas the older respondents $>80$ with other source of income; the difference in the observable preference for retirement neighbourhood can be traced to age instead of income source as initially suggested. Similarly, the tendency for more male respondents to have own income or receive transfers from either children or relatives would make them more agreeable to the retirement neighbourhood idea. Examination of partial tables for both male and female elderly respondents shows that there was a significant difference among female elderly which influenced their preference for retirement neighbourhood. There were more females with own income (53.7\%) and recipient of income from children and relatives (43.9\%) who prefer retirement neighbourhood compared to female elderly reporting income from other sources $(2.4 \%)$.

Preference for retirement neighbourhood nonetheless, remains significantly different among the different satisfaction levels; $72.9 \%$ among the satisfied elderly, followed by $21.9 \%$ among the very satisfied elderly and only $5.2 \%$ dissatisfied elderly. Using the chi-square tests for three-way tables, pegged at a significant level of $0.05(\mathrm{p}<0.05)$, the study also found that working status and medical condition among the satisfied elderly respondents tended to be associated with the preference for retirement neighbourhood. In general, the retired elderly who recorded satisfaction with life tend to prefer retirement neighbourhood (95.1\% compared to $33.0 \%$ elderly with similar working status and life satisfaction who chose nursing home). Similarly, the majority of the elderly (95.8\%) who reported good medical condition and also reported satisfaction with life tended to be associated with the preference for retirement neighbourhood compared to none of those elderly with the same characteristics who prefers nursing homes. In other words, Chinese elderly who are male, moderately old, and generally satisfied with life tend to prefer retirement neighbourhood as an alternative living arrangement to spend their retirement life. The findings of this study indicated that being retired and in good medical condition increase the elderly's satisfaction to life, which in turn influence their positive perception of retirement neighbourhood compared to nursing home.

Increased exposure to the new concept which was further explained in the interview session tend to influence the decision among younger retirees indicating a strong desire to live an independent and modern lifestyles afforded by retirement neighbourhood. The appeal of retirement neighbourhood becomes more apparent when they were explained about the functions of retirement neighbourhood as its concept takes into consideration every aspect of needs of the elderly people and provides a dignified life for the residents. Being retired means more leisure, and good medical condition means they can fully take part in the retirement neighbourhood social activities. The attractiveness of retirement neighbourhood also lies in its integrated infrastructure, facilities and services to 
Norhaslina Hassan, \& Tan Jiaqi

Preference for Purpose Built Retirement Neighbourhood Among the Chinese Elderly in Small Towns in Malaysia

cater for the needs of the elderly with much flexibility in housing types. The older respondents (> 80 years) in the sample, however, tend to prefer the more familiar nursing home because of limited exposure to the newer retirement neighbourhood concept. Most of the older respondents were also associated with lower life satisfaction and unreliable source of income, which present realistic limitation to their ability to even entertain the idea of living in retirement neighbourhood. The other reason was related to their limited physical movement, as most of them were unable to move actively, rendering social activities as promoted in retirement neighbourhood unattractive to them.

\section{PROMOTING RETIREMENT NEIGHBOURHOOD AS A DEVELOPMENT STRATEGY IN SMALL TOWNS}

Developers in Malaysia were quick to respond to the increasing awareness that nursing homes cannot provide satisfactory and comprehensive retirement life for the elderly in spite of the advanced medical health care. Already, major developments in the third-age retirement housing market have been constructed in Johor Bahru metropolitan area which include Platinum Residences in Lakehill Resort City and Leisure Farm Resort, located near a Columbia Asia hospital which boast multigenerational living opportunities. Other prominent providers in the fourth-age residential care market in Johor Bahru include a 200-bed facility by ECON Healthcare with in-home care, day care, rehabilitation, nursing home and acute care facilities; and Jeta Care, an 80-bed assisted-living facility and nursing home boasting a combined Western residential care concept with Confucian values (Ormond, 2014).

Coulson and Kim (2000) reiterate that the impact of real estate investments including elderly settlements on income to localities is much more significant than non-residential investments. The effect is through employment, savings, total investment and labour productivity (Harris \& Arku, 2006). This is in addition to the basic assumption that the importation of wealth afforded by amenity-seeking retirees into non-metropolitan areas would increase local economic activity through demand for locally provided services. The economic effects result from activities such as construction of infrastructure, property sales, operation and maintenance of the retirement neighbourhood, and expenditures by residents and visitors for more "urban" services that provide jobs and income for the locals. The fiscal effects result from changes in local government revenues from taxes, and changes in costs for providing public goods and services to residents of the retirement communities (Stallmann \& Jones, 1995). Purposely built retirement neighbourhood in small towns are not only targeting for amenity seeking retirees who are normally attracted to the environmental amenities in the rural areas but are also providing an alternative for local elderly who are blessed to receive financial support from their working children or earning their own income but having to live independently. 
It has been well established that older adults prefer to remain in their own homes, if at all possible (Leith, 2006; Keenan, 2010). Based on the interviews, it was found that the majority of the elderly respondents (96\%) insisted on staying in Segamat even though their family or children have requested them to move in with them to other areas where they were currently making a living. Many of the elderly respondents pointed that Segamat was their birth place and they were so used to its surroundings. Earlier findings showed that the average length of stay in Segamat for the sampled elderly was 60 years, which explains the emotional and psychological attachment to the place. In recognition of this pervasive desire to age in place, attention to ways to facilitate the elderly to be able to stay in their homes, such as providing services, both home- and community-based and new smart home technologies will be the way to go (Glass \& Skinner, 2013). Nonetheless, the overwhelming preference for retirement neighbourhood as revealed above increases the feasibility of planning for this type of elderly living arrangement in the Segamat.

\section{Planning for Retirement Neighbourhoods: The Case of Segamat}

While retirement townships that are provided by the private sector are envisaged to further stimulate local economic development, there is a significant role to be assumed by the local authority in order to ensure a well-functioning real estate market. The Segamat District Council, in regulating the physical development in its area and in line with its own objectives, performs duties such as facilitating land development by processing all applications for planning permission in accordance with the current planning standard requirements and development strategies as stipulated in the Local Plan. A retirement neighbourhood would support very much the overall development strategy of the local planning authority as much of its efforts is focused on promoting economic growth by attracting people to Segamat whether as residents, tourists, visitors or investors. A series of planning strategies, contained in the Local Plan for the Segamat District that is aimed to boost the local economy include new projects and development in business, agriculture, tourism and physical infrastructure (DTCP, 2010). A more complete transportation and road networks system was also proposed in the Plan. The Plan also seeks to tap the benefits of the double tracking railway project that runs from Seremban to Tanjung Pagar in Singapore as Segamat is situated at the middle between Kuala Lumpur and Singapore. The project would reduce travel time between Singapore and Kuala Lumpur from approximately 6 hours to about only 90 minutes.

Primarily, owing to its rich natural resources endowment, Segamat is planned as an agricultural and eco-tourism dominant area (DTPC, 2010). A number of scholarly articles have also discussed the ways in which natural amenities, especially public lands and other protected areas, stimulate economic 
Norhaslina Hassan, \& Tan Jiaqi

Preference for Purpose Built Retirement Neighbourhood Among the Chinese Elderly in Small Towns in Malaysia

growth by attracting individuals, small businesses, and retirees with non-earnings income, contributing to a variety of multiplier effects (Nelson 2006; Serow 2003; Chen \& Weber, 2014). Seen from this light, the planning efforts by the local planning authority to improve the general amenity of the area as well as facilitating efficient land development process that is in congruence with its development strategy will further increase the attractiveness of private sector investment in the elderly housing market in Segamat.

The economic opportunity presented by the increasingly mobile Asian retirees especially Singaporeans would be enhanced by the railway double tracking project, which would make Segamat more accessible from both north and south. It was reported that from 2002 to 2012, some 883 Singaporeans of a total 12,000 have taken advantage of the Malaysia My Second Home (MM2H) program, which is targeted at foreign retirees (Wong \& Ghazali, 2014). Cheaper retirement care in Johor, which ranges from USD480-630/month, as compared to facilities in Singapore (USD 700-3,500/month), would be a factor to attract foreign retirees to Johor (Ormond, 2014). Furthermore, given that the Johor Bahru metropolitan area is increasingly congested and highly priced, partly due to Singaporean induced demand, development of a more affordable retirement neighbourhood in Segamat is viable because of the lower cost of land compared to other districts especially Johor Bahru. This would enable Segamat to carve out its own retirement housing market in the lower and upper middle-income section whereas Johor Bahru would retain its position in major developments of retirement care facilities catering for the high-income market.

\section{CONCLUSION}

Malaysia will face the reality of an ageing population in less than 25 years. Many of its smaller towns such as Segamat have started to age due to the general trend of low fertility rate, longevity and specifically the migration of the young generation to the big cities for education or job opportunities, leaving their elderly parents behind in the small towns. Other demographic trends also raise the possibility that the younger generation, double income and smaller households may increase the demand for retirement neighbourhoods to support their elderly parents. This is also in cognizant of the undesirability of nursing homes as a place to spend their retirement life especially among the Chinese elderly. A seemingly new concept in Malaysia, retirement neighbourhoods have long been experimented with measurable success in countries such as United States, Australia and China. Retirement neighbourhood is a purpose built physical infrastructure, facilities and support services designed for independent living and active ageing with continuous care for the elderly. From the perspective views of current living arrangement, life satisfaction and its widespread acceptance as revealed in the study, retirement neighbourhood can become an alternative living option for the elderly in the future particularly in smaller towns such as Segamat. 
PLANNING MALAYSIA

Journal of the Malaysia Institute of Planners (2017)

Despite the pervasive desire to age in place, the local Chinese elderly find retirement neighbourhood an attractive option if built in Segamat as it involves short distance relocation and a definite option if they had to choose between nursing home and another alternatives.

It is feasible for the planning of the retirement neighbourhoods in Segamat as a means of capturing the advantages of this new elderly lifestyle preference. The promotion of purposely built retirement communities has a long history in rural economic development which focuses on rural amenity in order to attract retirees. Investment in retirement neighbourhoods in Segamat is expected to promote multiplier effects throughout the local economy via demand of its upstream and downstream industries. The local economic development would be triggered by opening up the elderly housing market in Segamat which enjoys competitive advantage based on several observable factors. Apart from its ageing population and receptive attitude towards the new retirement neighbourhood concept, its strategic location coupled with enhanced accessibility, the lower cost of land, as well as current and planned developments by the local planning authority contributes significantly toward increasing the viability of a retirement neighbourhood in Segamat. The serenity associated with the rural characteristic with minimal pollution, also makes Segamat a good living environment for retirees. While the increasing number of older people is viewed as a blight for rural areas in Britain (Butler, Morris \& Wright, 2003), this study see it as an opportunity that can support the overall development strategy of small towns in Malaysia.

Finally, since this study is limited on Chinese elderly only, studies that focus on other races are needed given that Malaysia is a multiracial society comprising of three main races; Malay, Chinese and Indian. As these races greatly differ in many aspects such as beliefs, culture and religious teachings, it is expected that there would be differences in terms of living requirements when taking care of their elderly parents. 
Norhaslina Hassan, \& Tan Jiaqi

Preference for Purpose Built Retirement Neighbourhood Among the Chinese Elderly in Small Towns in Malaysia

\section{REFERENCES}

Bernard, M., Liddle, J., Bartlam, B., Scharf, T., \& Sim, J. (2011). Then and now: evolving community in the context of a retirement village. Ageing and Society, 32(1), 103-129.

Butler, H., Morris, C., \& Wright, E. (2003). The demography of rural areas: A literature review, Cheltenham. Countryside and Community Research Unit and University of Gloucestershire.

Chan, M. E. (2011). Reasons of elderly people refuse to stay in nursing home. Retrieved April 17, 2015 from http://www.yanglao.com.cn/article/3439.html

Chen, Y., \& Weber, B. A. (2014). Natural capital and rural wealth creation: Federal forest policy and community vitality in the Pacific Northwest. In J. L. Pender, B. A. Weber, T. G. Johnson, \& J. M. Fannin (Eds), Rural wealth creation (pp. 185-200). New York: Routledge.

Coulson, N. E., \& Kim, M. S. (2000). Residential investment, non-residential investment and GDP. Real Estate Econ, 28, 233-247.

Crisp, D. A., Windsor, T. D., Butterworth, P., \& Anstey, K. J. (2013). What are older adults seeking? Factors encouraging or discouraging retirement village living. Australasian Journal on Ageing, 32(3), 163-170.

Department of Statistics Malaysia (2000). Housing and Population Census. Kuala Lumpur: Government Press.

Department of Statistics Malaysia (2010). Housing and Population Census. Kuala Lumpur: Government Press.

Department of Town and Country Planning Peninsular Malaysia [DTCP] (2010). Segamat District Local Plan 2020. Kuala Lumpur: Government Press.

Fagan, M., \& Longino, C. F. (1993). Migrating retirees: a source for economic development. Economic Development Quarterly, 7, 98-106.

Glasgow, N. (1990). Attracting retirees as a community development option. Journal of the Community Development Society, 21, 102-114.

Glass, A., \& Skinner, J. (2013). Retirement communities: We know what they are ... or do we? Journal of Housing for the Elderly, 27(1-2), 61-88.

Harris, R., \& Arku, G. (2006). Real estate and economic development: the evolution of an idea since 1945. Habitat International, 30, 1007-1017.

Hunt, M. E., Feldt, A. G., Marans, R. W., Pastalan, L. A., \& Vakalo, K. L. (1984). Retirement communities: An American original. New York: Haworth.

Izuhara, M. (2010). Housing wealth and family reciprocity in East Asia. In M. Izuhara (Ed.), Ageing and intergenerational relations: family reciprocity from a global perspective (pp. 77-94). Bristol: Policy Press.

Keenan, T. A. (2010). Home and community preferences of the 45+ population. Washington DC: AARP. 
Latham, J. R. (2013). A framework for leading the transformation to performance excellence part I: CEO perspectives on forces, facilitators, and strategic leadership systems. Quality Management Journal, 20(2), 22.

Leith, K. H. (2006). Home is where the heart is . . or is it? A phenomenological exploration of the meaning of home for older women in congregate housing. Journal of Aging Studies, 20, 317-333.

Lim, W.W.X., Noralfishah, S., \& Baldry, D. (2013). A conceptual framework for understanding the social care facilities management audit at the residential care home for the elderly in Malaysia. In Proceedings of the International Conference on Management Economics and Finance, Kota Kinabalu, Sabah.

Nelson, P. B. (2006). Geographic perspective on amenity migration across the USA: National, regional, and local scale analysis. In L.A.G. Moss (Ed.), The amenity migrants: seeking and sustaining mountains and their cultures (pp. 55-72). Cambridge, MA: Cromwell Press.

Ormond, M. (2014). Resorting to plan J: Popular perceptions of Singaporean retirement migration to Johor, Malaysia. Asian and Pacific Migration Journal, 23(1), 1-26.

Phillipson, C. (2010). Globalisation, global ageing and intergenerational change. In M. Izuhara (Ed), Ageing and intergenerational relations: family reciprocity from a global perspective (pp. 13-28). Bristol: Policy Press.

Reynolds, S. G., \& Beamish, J. O. (2003). Residential satisfaction of older adults in age-segregated facilities. Housing and Society, 30(1), 33-49.

Serow, W. (2003). Economic consequences of retiree concentrations: a review of North American studies. The Gerontologist, 43(6), 897-903.

Stallmann, J. I., \& Jones, L. L. (1995). A typology of retirement places: A community analysis. Journal of the Community Development Society, 26(1), 3-14.

Stallmann, J. I., \& Siegel, R. B. (1995). Attracting retirees as an economic development strategy: Looking into the future. Economic Development Quarterly, 9(4), 372-82.

Stimson, R., \& McCrea, R. (2004). A push - pull framework for modelling the relocation of retirees to a retirement village: the Australian experience. Environment and Planning A, 36, 1451-1470.

Tan, S. J. (2014). Pull Back Segamat into the Pathway of Development. Retrieved June 16, 2015 from http://mykampung. sinchew.com.my/node/288718?tid=59

Toyota, M., \& Xiang, B. (2012). The emerging transnational "retirement industry" in Southeast Asia. International Journal of Sociology and Social Policy, 32(11/12), 708-719. 
Norhaslina Hassan, \& Tan Jiaqi

Preference for Purpose Built Retirement Neighbourhood Among the Chinese Elderly in Small Towns in Malaysia

United Nations Department of Economic and Social Affairs, Population Division (2013). World Population Ageing 2013, ST/SEA/SER.A/348. New York: United Nations Publication.

Wong, K. M., \& Ghazali, M. (2014). Retirement motivation among 'Malaysia My Second Home' participants. Tourism Management, 40, 141-154.

Wong, L. (2011). Reasons of elderly people refused to stay in nursing home. Retrieved April $\quad 15, \quad 2015$ from http://www.yanglao.com.cn/article/3439.html 